\title{
El cine detectivesco de Cifesa a través de sus personajes
}

Jorge Chenovart González | j.chenovart@gmail.com Universidad de Valencia, España

\section{Resumen}

Palabras clave

"Cine detectivesco"; "Cifesa"; "Actante";

"Personaje"; "Cine español".

Sumario

2. Marco teórico.

3.Contexto.

4. Estudio comparative de los personajes.

5. Conclusiones.

6. Referencias bibliográficas.
1. Introducción.

El cine español tiene como referente fundamental en su historia a

la productora valenciana Cifesa. Su producción se caracterizó por una fuerte apuesta por contenidos costumbristas, en ocasiones de corte folclórico, así como por enaltecer los valores patrios a través de películas de corte histórico. La presente investigación ahonda en un determinado sector de obras de corte detectivesco, las cuales supusieron pequeñas rarezas en la producción de la compañía. Las películas fueron cuatro: El 13-13, Eloísa está debajo de un almendro, La culpa del otro y El Clavo. Para entender cuáles son los modelos de representación del cine detectivesco en Cifesa, se analizarán los personajes a través de diferentes metodologías: estudio actancial, formación del personaje e instantes narrativos esenciales. De esta manera, se podrá comprender cómo se enfocó en Cifesa, la investigación detectivesca en sus diferentes vertientes: comedia, drama, surrealismo o tragedia, entre otras.

\section{Cómo citar este texto:}

Jorge Chenovart González (2020): El cine detectivesco de Cifesa a través de sus personajes, en Miguel Hernández Communication Journal, Vol. 11 (2), pp. 277 a 296. Universidad Miguel Hernández, UMH (ElcheAlicante). DOI: http://dx.doi.org/10.21134/mhcj.v11i0.334 


\section{The detective cinema of Cifesa through its characters}

Jorge Chenovart González | j.chenovart@gmail.com Instituto Politécnico de Viseu, Portugal

\author{
Abstract \\ Keywords \\ "Detective cinema”; "Cifesa”; "Actant"; “Character"; \\ "Spanish cinema". \\ Summary \\ 1. Introduction. \\ 2. Theoretical framework. \\ 3.Context. \\ 4. Comparative study of the characters. \\ 5. Conclusions. \\ 6. Bibliographical references.
}

The Valencian cinema producer Cifesa is a fundamental reference in the history of cinematography in Spain. His production was based on folkloric, folkloric and historical films that showed patriotic values. The present investigation is introduced in a certain sector of detective films, small oddities in the production of Cifesa. The movies was four: El 13-13, Eloísa está debajo de un almendro, La culpa del otro and El clavo. To understand the models of representation of detective cinema in Cifesa, the characters of each film will be analyzed through different methodologies: actantial study, character formation and essential narrative instants. In this way, it will be possible to understand how Cifesa focused on detective research in its different aspects: comedy, drama, surrealism or tragedy, among others.

How to cite this text:

Jorge Chenovart González (2020): The detective cinema of Cifesa through its characters, in Miguel Hernández Communication Journal, Vol. 11 (2), pp. 277 a 296. Universidad Miguel Hernández, UMH (Elche-Alicante). DOI: http://dx.doi.org/10.21134/mhcj.v11i0.334 


\section{Introducción}

El presente artículo se concibe como un texto cuya estructura sigue un proceso analítico en el que todas sus partes se encuentran interrelacionadas. Manteniendo esta premisa, el marco teórico se fundamenta mediante la conjugación de los siguientes aspectos:

-Contextualización de la producción de Cifesa.

-Aproximación a conceptos que permiten entender el cine de carácter detectivesco que posteriormente se analizará.

-Las metodologías relacionadas con el desarrollo y evolución del personaje en el relato cinematográfico.

Establecida la vertiente teórica, se estudiarán los rasgos más característicos de cada una de las obras, de manera que puedan entenderse como películas de corte investigativo, así como sus personajes esenciales que dan forma al propio relato.

Posteriormente, se llevará a cabo un análisis del personaje de cuatro películas que mantienen vínculos con el cine detectivesco teniendo en cuenta las siguientes cuestiones:

-Metodología actancial de Greimas.

-El personaje como elemento narrativo redondo.

-Instantes esenciales que dan continuidad a la película (sucesos núcleo).

En última instancia, se llevarán a cabo las conclusiones pertinentes.

\section{Marco teórico}

\subsection{Cifesa: rarezas detectivescas entre el folclore, el costumbrismo y la historia}

El cine español tiene como referente histórico, en términos de producción y distribución fílmica, a la productora valenciana Cifesa. La autodenominada "Antorcha de los éxitos" produjo (sumando las coproducciones) más de ochenta entre los 1934 y 1951, teniendo como inicio La bermana San Sulpicio (Florián Rey, 1934) y concluyendo con la coproducción hispano-argentina de índole menor, Una cubana en España (Luis Bayón Herrera, 1951).

La trayectoria de Cifesa se encuentra marcada por unos mandamientos (Fanés, 1989:52) que, si bien establecieron en sus inicios (periodo republicano), quisieron mantenerse en esencia durante las posteriores décadas en el periodo franquista, aunque en este caso, sin mantener convenios de colaboración con grandes distribuidoras americanas, especialmente Columbia, de la que fue una hermana hasta el acercamiento al régimen franquista (Noticiario Cifesa, 1939, 19). Estos mandamientos, fueron el resultado de la sinergia formada por los siguientes elementos: la alta burguesía valenciana de corte cristiano conservador, con la familia Trénor a la cabeza; estrategias de marketing capitalistas emulando el modelo de Star-System (Comas, 2004); y un respeto absoluto por el público, el cual debe ser entretenido constantemente.

Este último aspecto se verá enturbiado por la citada aproximación a Franco, siendo considerada como la productora del régimen y, aislada de sus ambiciosos proyectos norteamericanos, se verá abocada a la producción constante de comedias de corte costumbrista, alternando con obras 
de mayor calado, especialmente históricas, rememorando un antiguo espíritu épico (SánchezBiosca, 2012: 501) como Agustina de Aragón (Juan de Orduña, 1950) o adaptaciones literarias como Pequeñeces (Juan de Orduña, 1950). Apoyando esta línea, Gutiérrez (2016: 248) señala lo siguiente:

la construcción de un estado nacional en el que la religión, los valores tradicionales, la eliminación de cualquier cuestión relacionada con la República, un alejamiento del comunismo o del liberalismo, frente a la exaltación patriótica apoyado por un fuerte apartado militar, conformarán la base esencial de la nueva España que Franco quería imponer.

Haciendo balance de la producción de Cifesa, encontramos tres etapas fundamentales en su camino cinematográfico (Chenovart, 2016: 1116): la etapa republicana (1934-1936) con obras consideradas como capitales en el cine español, como La verbena de la Paloma (Benito Perojo, 1935), Morena Clara (Florián Rey, 1936) o Nobleza Baturra (Florián Rey, 1935); la etapa costumbrista, en la que se encuentran obras de corte militar como jHarka! (Carlos Arévalo, 1941) y A mí la legión (Juan de Orduña, 1942), comedias románticas como La chica del gato (Ramón Quadreny, 1943), Huella de luz (Rafael Gil, 1943) o La boda de Quinita Flores (Gonzalo Delgrás, 1943); y la etapa de recreaciones históricas, donde el desembolso económico iba acompañado de la encarecido interés por rememorar las gloriosas gestas históricas españolas, como La leona de Castilla (Juan de Orduña, 1951) o Alba de América (Juan de Orduña, 1951). Interesante es la afirmación de Franco i Giner (1998: 152) que engloba la producción fílmica:

Si observamos brevemente lo puesto de manifiesto por Cifesa podría resumirse así: canto lírico de la Decadencia durante la República; canto épico de la Decadencia durante la Autarquía; canto epigonal de la Decadencia y agónico por no sentirlo ya como propio durante los años de apertura del régimen.

Sin embargo, durante la segunda etapa en plena posguerra, hubo algunas excepciones de carácter detectivesco, que supusieron, por un lado, aportaciones novedosas dentro de la producción de Cifesa y por otro, adaptaciones literarias que mejoraban el nivel productivo de la compañía, creando un cine de investigación de carácter nacional (Rodríguez Fuentes, 2012: 48). Esas cuatro obras fueron El13-13 (Luis Lucia, 1944), única obra de producción propia enmarcada en el característico cine negro; Eloísa está debajo de un almendro (Rafael Gil, 1943), tragicomedia romántica, teatral y surrealista; La culpa del otro (Ignacio F. Iquino, 1942), exponente de Cifesa de la estratificación de las clases sociales y El clavo (Rafael Gil, 1944), adaptación literaria que engloba los géneros dramático y judicial.

\subsection{Acercamiento al cine detectivesco}

En el presente apartado, se propone acercar al lector de una manera simple y coherente al cine detectivesco, mediante definiciones concretas y conjunciones que intenten encuadrar lo que posteriormente se analizará.

En todo filme que se precie de corte investigativo, el conflicto, componente primordial en todo relato (Prósper, 2019: 309) aparece de manera paulatina, dando "coherencia a los demás elementos de la construcción narrativa, a saber: la trama, la acción y el personaje" (Benavides, 2012:161). De manera sencilla y pragmática, podría entenderse el cine detectivesco como aquel en el que existe un caso que debe resolverse, sea cual sea y en el que uno o varios determinados personajes inician una investigación. Más allá de encasillar, en primera instancia, un cine con características reseñables para el imaginario colectivo, centrarse en la palabra "detective" implica 
entender que un personaje puede ejercer este oficio sin vivir de ello, obteniendo el objetivo marcado. Lo detectivesco, insertado en el imaginario colectivo a partir del cine negro de los años 30 en Estados Unidos, mantiene un vínculo existencial y coyuntural con el thriller y lo policiaco. Para establecer un terreno básico sobre el que trabajar, se seguirán las pautas de Andrade Boué (2010: 6):

La ductilidad de la novela policiaca se basa paradójicamente en que su estructura es rígida: 1) Presentación en la que detective (o policía o amateur) busca resolver un enigma y atrapar a un criminal. 2) Nudo (investigación propiamente dicha). 3) Desenlace, en el que se resuelve el enigma y se da captura al criminal

En cuanto al cine negro, Sánchez Noriega (2008, 27-34) advierte de su carácter idiosincrático cuando se estrenaron en Francia El halcón maltes (The Maltese Falcon, John Houston, 1941), Perdición (Double Idemnity, Billy Wilder, 1944), Laura (Otto Preminger, 1944), Historia de un detective (Murder, My Sweet, Edward Dmtryk, 1944)) y La mujer del cuadro (The Woman in the Window, Fritz Lang, 1944). Así pues, afirma que:

El cine negro adquiere carta de naturaleza cuando se estrenan en Francia [...] y la crítica bautiza en francés, y luego en inglés como film noir, por la semejanza en el clima y la temática criminal con las novelas de la titulada Série noire de Gallimard, cuyas cubiertas tienen fondo de color negro.

Asimismo, Sánchez Noriega matiza algunos elementos clave como los personajes estereotipados, historias violentas o fuertemente dramáticas, conflictos sesgados por un contexto social jerarquizado, expresionismo artístico, algo que reafirma Coma (1991) con personajes situados al margen de la ley con diálogos cortantes y cínicos. Asimismo, Russo (1998: 32) matiza y aporta a partir de las obras norteamericanas citadas anteriormente, diferencias entre el gangster film y lo policial:

lo que en el gangster film llevaba la ficción a lo realista, en el policial negro se convirtió en un universo casi pesadillesco. En ese género donde el crimen se convierte en una posibilidad cierta, inmediata a escala privada. [...] el cine negro ya se asienta en un mundo de apariencias engañosas [...] el policial negro sólo es tal por costumbre nominatoria. En realidad, lo que nunca falta en él es el crimen.

Estos elementos transportan al espectador y le alejan de una perspectiva optimista en el relato, poniendo el foco en una sociedad triste, cuyos referentes temáticos se encontraban en los límites de la ley (Benet, 2014: 11). Sin duda, una atmosfera fantástica para crear un tejido puramente policiaco (Medina de la Viña, 2017: 16), que suponga la fusión de géneros. De esta manera, Hueso Montón (1988: 377, en Medina de la Viña, 2017: 16) mantiene que contadas corrientes han mantenido un estilo estético y un planteamiento técnico que pueda ser todavía valorado y determinado como una corriente propia.

Este planteamiento mantiene unas líneas generales que engloban al cine detectivesco como un todo, pero resulta interesante la aportación de Paszkiewicz (2007: 91-92) que siguiendo a Gledhill (1998) sostiene que hay diferencias sobre el detective en función del género. Mientras que el detective masculino no solamente averigua datos sobre el caso, sino que también se ve abocado al descubrimiento de la mujer que tiene al lado, esta, generalmente delimitada en la seducción como arma, no mantiene una fuerza investigadora. Esta realidad, como veremos, queda alejada en las tramas de la filmografía escogida. 


\subsection{Metodologías de análisis del personaje}

La metodología de análisis que debe ayudar a comprender el transcurso del personaje en el relato se inicia con el modelo actancial de Julius Argidas Greimas (1966), quien, desde una perspectiva estructuralista inspirada en la corriente formalista soviética, propone la figura del actante como elemento para concebir la acción del personaje. Siguiendo al autor, un personaje puede ejercer un total de seis funciones actanciales: sujeto, quien realiza principal en el relato teniendo siempre en el horizonte un objetivo; objeto, aquello que persigue el sujeto; ayudante, actante que se encuentra al lado de manera positiva para el sujeto en pro de la intención final de este; oponente, quien pone obstáculos para que el objetivo sea finalizado según la necesidad del sujeto; destinador, aquel que desencadena la acción del sujeto; y destinatario, sobre el que recae la consecución del objetivo.

A través de estos seis elementos, ya se pueden extraer aspectos que ayudan a entender el transcurso del personaje a lo largo de la narración. No obstante, será necesario diferenciar a los personajes en función de su evolución durante la obra, concibiendo, con Forster (1983) como referente, la diferenciación de personajes planos y redondos. Los primeros serían aquellos que no muestran atisbos de evolucionar en la historia, ni tan solo en los momentos clave de misma. Los segundos, aquellos que muestran un desarrollo propio, adaptándose a las vicisitudes de su trayectoria vital, generando giros inesperados constantes (García Jiménez, 1993: 304).

Si los actantes ayudan a entender las funciones del personaje en la obra y las acciones generan progresos en los mismos, resultaría adecuado remarcar aquellos instantes narrativos que generan cambios en el desarrollo del relato y que por tanto son esenciales para el avance del personaje. Estos momentos son los llamados sucesos núcleo (Chatman, 1990: 57). Por otro lado, existen los sucesos satélite, aquellos que no aportan un interés al relato, pero enriquecen su propio universo (Prósper, 2004: 12).

La sinergia entre estas tres formas de comprender una narración permite:

- Conocer cuáles son los personajes esenciales del relato dentro del cine detectivesco

- Averiguar si existen patrones de similitud en las producciones de este corte cinematográfico en Cifesa.

- Entender las relaciones entre la mujer y el hombre en relato y saber cómo actúan en función de sus pretensiones.

Por último, cabe destacar que la reminiscencia formalista sempiterna en las políticas estructuralistas que se llevan a cabo evidencia la necesidad de emplear el esquema canónico narrativo (Greimas y Courtes, 1982: 275) del héroe a través de la figura de Propp y su Morfología del cuento, para poder situar a los personajes protagonistas y secundarios en una misma órbita de sucesos núcleo. Se verá, a través de las acciones del personaje (Betancur, 2005: 22), si el héroe se encuentra calificado para la realización de pruebas heroicas y de recompensas.

\section{Contexto}

En las cuatro películas a analizar hay un común denominador, algo que investigar y resolver. Si bien, únicamente El 13-13 cumple con los cánones clásicos de cine de espionaje, siendo el protagonista un profesional del terreno, tanto Eloísa está debajo de un almendro, El clavo como en La culpa del otro mantienen una trama detectivesca por parte de los actantes sujeto que ofrece una vuelta de tuerca al modelo tradicional, especialmente por ser personajes que no se encuentran familiarizados de manera fehaciente en el ámbito policial. 


\subsection{Filmografía escogida}

\section{El 13-13}

Pablo y Berta se encuentran tras muchos años en una ciudad imaginaria de un país contrario a los valores españoles patrios del momento de filmación. Ambos desconocen el trabajo del otro, espías aliados en la misma compañía. A Pablo (el 13-13) siempre le encargan los casos más importantes y Berta (la 13-14) se encuentra recelosa de ello (aún sin saber que Pablo es el 13-13). Cuando a él le encargan la misión peligrosa para acabar con unos espías extranjeros, ella insistirá en participar y demostrar su valía.

\section{La culpa del otro}

Rafael y Carolina son acusados de robo en la casa de un marqués, lugar donde trabajan. El delito está organizado por el administrador, Ludovico, enamorado de ella. Años después María del Carmen, hija de ambos, inicia la investigación del caso para ayudar al nuevo marqués, del que se ha enamorado perdidamente.

\section{Eloísa está debajo de un almendro}

La investigación se inicia cuando Fernando llega a casa después de diez años en el extranjero y encuentra una nota de suicidio de su padre, encargándole que investigue el caso de la muerte de la mujer que amó, Eloísa, hecho que le llevó a quitarse la vida. A partir de este instante, inicia la investigación de la mano de la hija de Eloísa, cuyo encuentro entre ambos genera un enamoramiento mágico e involucrará de lleno a las dos familias.

\section{El clavo}

Narra la historia de amor entre Javier y Blanca. Él es un futuro juez y ella, una dama que huye de un pasado tormentoso. Cuando ella decide desaparecer la vida del protagonista cambia por completo, dedicándose al trabajo y reabriendo un caso de un asesinato que no fue correctamente investigado, la muerte de un hombre con un clavo incrustado en el cráneo. Los derroteros del sumario llevarán al descubrimiento de que Blanca fue quien mató al hombre en cuestión.

\subsection{Descripción de los personajes}

Los personajes que se muestran a continuación tienen un peso específico en la narración, obviando aquellos secundarios que ni fomentan una progresión narratológica ni cambian los quehaceres de los propios personajes que sostienen la obra. Por tanto, serán diferenciados entre personajes protagonistas y secundarios, explicando los porqués de esta distribución.

\section{El 13-13}

Los personajes protagonistas son Pablo y Berta. Como personajes secundarios, encontramos a Berkel, el coronel que guía las andanzas de los protagonistas y que ejerce de figura paternal y consejera. Entendemos que los antagonistas son secundarios ya que ayudan a enriquecer el relato cambiando la dirección de ambos. Por ello, Krugerin, trabajador de la agencia de espionaje, sobornado por los enemigos, y los espías de este bando, son secundarios con gran carga en la historia.

Respecto a los prototipos de personaje que desempeñan ambos, Pablo, ejerce de eje masculino, comprometido con su país, por tanto, patriota y protector, conquistador y galán respecto a Berta, al encargarse de la misión. Como detalle, el enaltecimiento del patriotismo se observa en la frase de Pablo: "no he dudado en dar todo por la patria".

Por su parte, Berta rompe con un modelo de mujer sumisa, siendo soltera y dedicándose a un 
trabajo con total disponibilidad, pero Pablo le enclava en una encrucijada entre amor y empleo. Aparecen rasgos femeninos modernos en Cifesa, ya que si bien la tónica productiva de la empresa mostraba a una mujer (al margen las películas históricas) ligada a los pasos del hombre, su personalidad y su compañera de piso, la cual se encuentra libre de la figura masculina, la distancia del arquetipo femenino.

En cuanto a los personajes secundarios, Berkel, como hombre, ejerce una función paternal, no solamente con Berta sino también con Pablo. Su respeto y cariño hacia ambos se deben a la confianza que muestra en las aptitudes de los dos. No obstante, observamos cierta debilidad en Berta cuando ambos retoman la historia de amor y es ella quien empieza a flaquear en sus misiones. Ahí es cuando Berkel adquiere un poder patriarcal explicándole que es difícil compaginar ambos campos para una espía.

Las acciones de los antagonistas se encuentran determinadas por la psicología de los mismos, especialmente los celos de Krugerin, un espía de segunda fila, que es fácilmente manipulable por los adversarios. Sobornado por estos, ofrece información sobre sus compañeros por dinero. Por otro lado, la psicología de los espías aparece sesgada por su función oponente. No hay un reflejo de la personalidad de ambos, evocando al clásico mercenario.

\section{La culpa del otro}

La culpa del otro también tiene una pareja mixta de protagonistas como principales personajes del relato. María del Carmen y Juan Carlos son la pareja que decide conocer la realidad en torno al suceso que ocurrió en la casa y que condenó a los padres de la joven al exilio (Rafael) y la prisión (Carolina).

En esta película aparecen un mayor número de personajes secundarios que aportan sustento al relato. Por un lado, los propios padres de Carolina. Por otro, los personajes que generaron el conflicto y que cambiaron el destino de la protagonista: Ludovico, administrador de la finca y enamorado de Carolina, quien genera la confusión que acaba cayendo en la condena de los padres de María del Carmen; Gregoria y Atilano, los padres adoptivos de la joven y quienes se han encargado de su educación; y Cornelio, el detective, que nunca creyó la acusación, retomando el suceso.

El encuentro entre Juan Carlos, nuevo marqués y María del Carmen, resulta necesario para la reapertura de la investigación. Él, perteneciente a una clase social alta y ella, educada bajo una mirada matriarcal enfocada en la cultura musical, transmiten al espectador la clásica relación que propone el canon cifesiano: joven adinerado y honrado se enamora de una chica universalmente atractiva y culta que necesita de su amado para resolver su caso.

En cuanto a los secundarios, debemos diferenciar entre oponentes y ayudantes, para entender mejor las características esenciales de los mismos. Bajo una tónica general de pertenencia a un estrato sociodemográfico bajo, los primeros, Ludovico y el Patrón se mueven de manera egoísta, el primero por amor-posesión y el segundo por dinero. Por su parte, los que ejercen una influencia positiva, Cornelio, Gregoria y Atilano, sirven de refuerzo, principalmente al objetivo de la protagonista. Cornelio es un policía fiel a sus principios de autoridad ciudadana. Mientras que Gregoria y Atilano, rompen con los estereotipos de pareja, siendo ella quien ejerce la autoridad en casa y el segundo, de fiel enamorado amo de hogar. En este sentido y para no romper con lo habitual en este tipo de relación, se trata desde una perspectiva cómica. 


\section{Eloísa está debajo de un almendro}

Fernando y Mariana son dos enamorados quieren resolver un misterio, la muerte de la madre de ella. La pareja protagonista se encuentra rodeada de personajes secundarios, la gran mayoría de ellos aportando relativamente poco a la propia investigación. Únicamente encontramos un ayudante en la resolución final del conflicto, el policía/detective, que, si bien no aparece durante el desarrollo de la película, sirve para poner el colofón investigativo al relato.

La unión entre ambos personajes protagonistas desde una vertiente sentimental, potencia el desarrollo de la investigación, ya que ambos personajes se encuentran unidos tanto por sus emociones como por las necesidades de conocer la realidad.

Es cierto que aparecen secundarios interesantes por su contenido cómico, creando un poso narrativo esencial para la obra, como el padre de Mariana (Edgardo) o Ezequiel (tío de Fernando) quien en primera instancia parece un antagonista de manual, con su oscurantismo. Sin embargo, no generan más que contexto cómico a la investigación, excepto al final cuando todos los personajes, en mayor o menor medida, se muestran relacionados con el caso (especialmente Edgardo como cónyuge de la asesinada).

\section{El clavo}

Mantiene similitudes con Eloísa está debajo de un almendro, ya que pese a haber un gran coro, simplemente la pareja protagonista (Javier y Blanca) y un personaje secundario, adquieren relevancia actancial en el relato. Este secundario es Juan, fiel escudero de Javier en el pequeño municipio y con quien traba una gran amistad, ayudando finalmente a que Blanca no sea condenada a muerte.

Encontramos en Javier y Blanca, dos personajes, a primera vista similares socialmente hablando, aunque veremos cómo ella se encuentra bajo un yugo económico, contexto del asesinato de la víctima.

\section{Estudio comparativo de los personajes}

El modelo de estudio se encuentra dividido en tres epígrafes: análisis actancial de cada obra para entender las relaciones entre personajes durante el relato; sucesos núcleo en los que los personajes protagonistas y secundarios relevantes cambian u ofrecen transformaciones en la narración; y personajes que evolucionan y se van construyendo a lo largo del relato a través de sus funciones en los momentos clave.

\subsection{Análisis actancial de las obras}

En primer lugar, veamos cuál sería el esquema actancial de cada película:

Figura 1: El 13-13. Fuente: Elaboración propia.

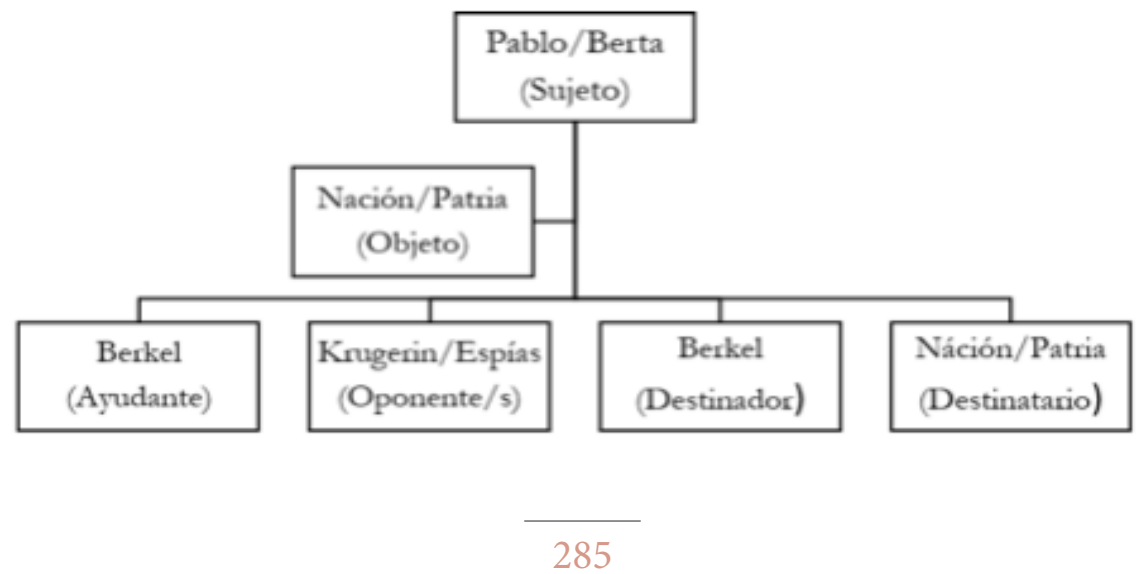


Se puede observar en El 13-13 (Figura 1), que tanto Pablo como Berta ejercen la función actancial sujeto ya que ambos compaginan su vida amorosa con la laboral, anteponiendo en ocasiones la segunda, reflejando la relevancia que tiene para estos su carrera vital. Este hecho sitúa exclusivamente la defensa de la nación como el objeto esencial del esquema. Ser fieles a la patria (algo característico en filmografía de la posguerra en Cifesa) es tan importante como enamorarse.

Como actante ayudante, el coronel Berkel no solamente ejerce de guía profesional de ambos, sino que también aporta dosis de serenidad al comportamiento impetuoso que ambos protagonistas tienen. Encuentran en él una figura paternal que es necesaria para compaginar la vida solitaria que durante mucho tiempo (el que transcurre hasta el retorno como pareja) han vivido. Por lo que respecta al papel de oponente, está representado por un modelo clásico en lo que a enfrentamiento entre bandos (en este caso de espías) se refiere. Tanto Krugerin como los dos espías que mantienen en jaque a los protagonistas y en definitiva a la agencia protagonista, ejercen una oposición constante ligada esencialmente al trabajo entre ambos, algo que no perturba de manera directa, sino colateral (la muerte de Pablo y la condena de Berta en los instantes finales), su relación amorosa.

Encontramos un destinatario coincidente con el objeto actancial principal, la protección de la nación de enemigos políticos. Este actante cierra un círculo que se inició con la misión que Berkel encarga a Pablo y que, trágicamente, concluye con la vida de este.

Figura 2: Eloisa está debajo de un almendro. Fuente: Elaboración propia.

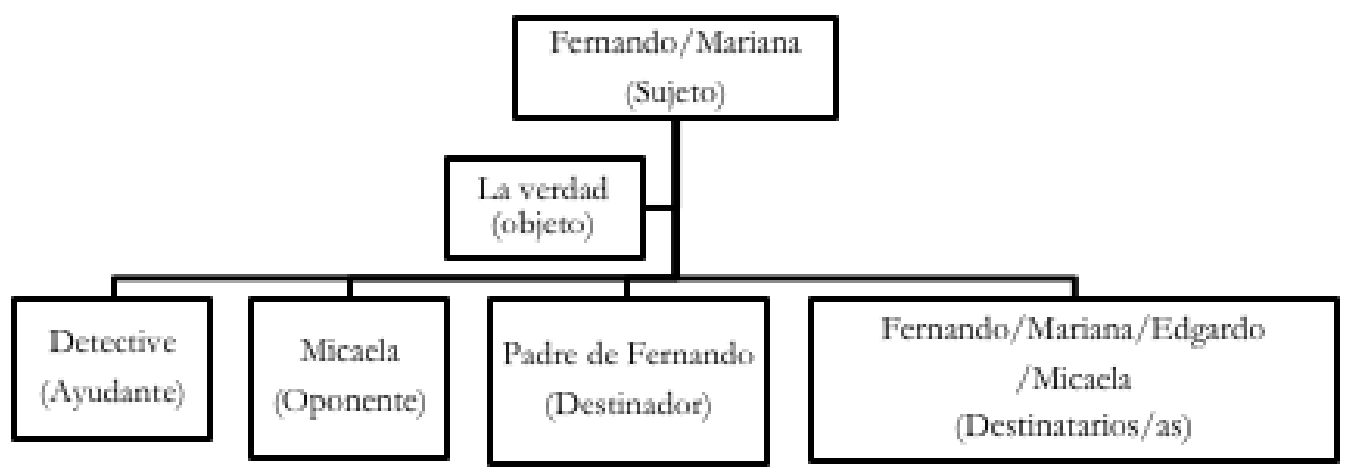

Eloísa está debajo de un almendro (Figura 2) dispone de dos sujetos unidos por una misma causa. Entendemos así, que, pese a que el enamoramiento entre ambos sirve para establecer vínculos que ayudan a la resolución del caso, ambos concluyen en que el objetivo principal es descubrir quién mató a la madre de Mariana. Sobre este caso gira la trama del relato.

A partir de aquí ya se pueden colocar los ayudantes y oponentes respecto a la resolución del conflicto. La relación, casi simbiótica, que hay entre ambos permite que aparezcan pocos ayudantes directos que permitan avanzar durante el camino. No obstante, el detective, con su aparición al final de la película, ayuda a conseguir la confesión de Micaela, quien en definitiva se ha visto forzada por los propios sujetos. De esta manera, la propia Micaela es la oponente del caso, intentando evitar a toda costa que las pesquisas se dirijan hacia su persona. 
Una obra en la que se entremezclan el enredo cómico con la intriga permite que un amplio coro forme parte de manera secundaria de la investigación. En primer lugar, el padre de Fernando sería el destinador, ya que es quien introduce en la investigación a raíz de su nota tanto a Fernando como Mariana. Sin embargo, el enamoramiento casi mágico por parte de él hacia ella reforzó el interés. En este caso, el número de destinatarios aumenta e incluye a la propia Micaela, como condenada final, al mismo tiempo que introduce a un nuevo personaje en el esquema, como es Edgardo, padre de Mariana y principal afectado por la misma, ya que su muerte le dejó en cama. Asimismo, el tesón mostrado por Fernando y Mariana comporta que sean también destinatarios.

Figura 3: La culpa del otro. Fuente: Elaboración propia.

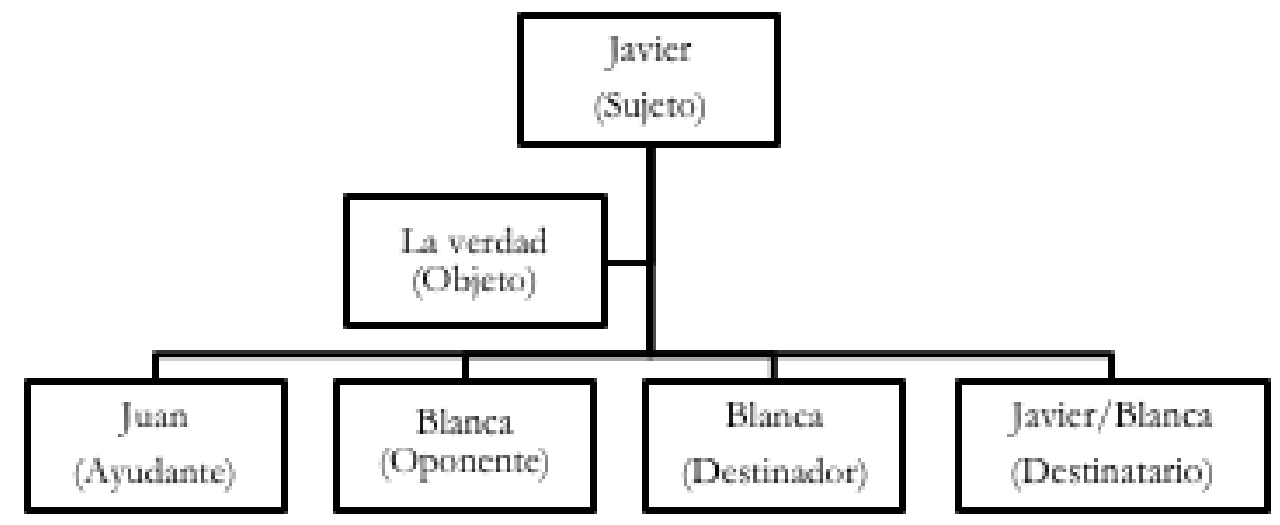

Para establecer un dibujo actancial (Figura 3) que ayude a comprender el desarrollo de la investigación, es importante tener en cuenta que puede haber otro que se encuentra paralelo a la acción pero que no se corresponde con la acción investigadora. Resultaría, por tanto, aceptable entender que Carolina es el sujeto que busca a su hija para, una vez salida de prisión, dar luz a la verdad. Sin embargo, la investigación la llevan a cabo dos personajes, María del Carmen y Juan Carlos. En este caso, la primera sería el sujeto de la historia al ser elemento central de la misma y siendo Juan Carlos un mero ayudante, de gran importancia, pero sin acción destinadora hacia sí mismo. El objeto sería Carolina, tanto por el encuentro con la hija, como por desvelar lo que ocurrió.

Juan Carlos es un ayudante enamorado, esto implica que, teniendo relación directa con el caso, su unión hacia María del Carmen posibilita la entrada, otra vez, de la familia en su mansión. Por otro lado, aparece la figura de un investigador, Cornelio, quien no se dio por satisfecho, uniéndose por segunda ocasión a la conclusión del caso. Por otra parte, el principal oponente es Ludovico, quien a su vez es destinador, ya que fue él quien generó el problema y condenó a los padres a la ruina existencial.

Mientras que la situación de Ludovico como destinador (y oponente) es clara, el anhelo por encontrarse con la hija permite situarlos como destinadores también, porque la hija conoce que es adoptada (por Atilano y Gregoria), hecho que aumenta las ganas de búsqueda de la protagonista. Como destinatarios, encontramos a la madre y la hija, cuya unión supone un rencuentro emotivo después de tantos años. 
Figura 4: El clavo. Fuente: Elaboración propia.

Las diferentes partes en las que se divide narrativamente (a través de elipsis temporales) El clavo, permiten concluir que el modelo actancial (Figura 4) esencial desde el punto de vista detectivesco lo encontramos con la llegada de Javier al pueblo, encontrándose solo y abandonado por Blanca. El inicio de una nueva investigación implica a Javier como sujeto de la misma, estableciéndose el propio caso, con su resolución, como objeto/objetivo.

El principal ayudante de la investigación es Juan, ya sea como secretario del juzgado donde admira a Javier, como en su intento por reducir una pena capital hacia la condenada. Evidentemente, la oponente sería la propia Blanca, quien tras el abandono a Javier y la propia autoría de los hechos, genera un problema moral al protagonista masculino.

Mientras Blanca ejerce de manera clara de actante destinadora ya que es la asesina del cadáver que encuentra Javier, como destinatarios, ambos aparecen en esta posición, ya que son sujetos activos de una relación finiquitada que paradójicamente les vuelve a unir de dramática manera.

\subsubsection{Paralelismos actanciales}

Ha quedado patente, en primer término, que las aventuras de los personajes cambian en función del contexto narrativo del relato. Sin embargo, el análisis de los personajes a través de la metodología actancial, permite extraer las siguientes analogías en la obra de corte detectivesco en Cifesa.

- En las cuatro hay una pareja como protagonista. Este hecho implica que siempre se dé una historia de amor que vincule a los personajes más importantes de la obra y que genere continuidad narrativa.

- El 13-13 y Eloísa está debajo de un almendro mantienen una correlación entre el protagonismo de la pareja y su función simultanea como actantes sujeto. Ambos trabajan de la mano o por el mismo objetivo.

- Hay una autoridad del ámbito militar o policiaco que efectúa tareas de ayudante en tres de las cuatro películas: El13-13, con Berkel; Cornelio en La culpa del otro; y el detective en Eloísa está debajo de un almendro.

- De los ayudantes citados, solamente en El13-13, actúa ayudando durante toda la narración, aspecto que le colocaría en un primer nivel. El resto de ayudantes colaboran de manera secundaria, aportando información ( La culpa del otro) o apareciendo de repente, ofreciendo sustento actancial al final de la obra (Eloísa está debajo de un almendro).

- En tres obras hay un caso como objeto con un vínculo sentimental (patria o amor) notable para los sujetos y protagonistas. No obstante, remarcaremos que La culpa del otro, tiene a Carolina como objeto primario ya que se encuentra dentro de la resolución propia del conflicto y, a diferencia de Eloísa está debajo de un almendro y El 13-13, continúa viva.

- En ocasiones, el oponente entorpece la consecución del objetivo porque es el propio destinador, como Ludovico (La culpa del otro) y Blanca (El clavo). 
- En las tres donde hay un misterio al uso (La culpa del otro, Eloísa está debajo de un almendro y El clavo), los destinatarios son los propios sujetos ya que hay se establece una acción catártica individual, a través de la investigación.

\subsection{Sucesos núcleo que cambian la dirección del relato}

Los sucesos núcleo son capitales para el enriquecimiento del relato y el mantenimiento de una velocidad constante del mismo, siendo los que fortalecen la atención del propio espectador y el interés respecto a los pasos de los personajes, tanto protagonistas como secundarios. Veamos a continuación cuáles son esos instantes esenciales.

\section{El 13-13}

El 13-13 muestra dos sucesos núcleo transcendentales respecto a la relación entre ambos personajes protagonistas y sus trabajos. El primero con el encuentro entre Pablo y Berta, que no solamente permite retomar la historia de amor sino conocer por parte de ella quién es ese 13-13 que siempre se le adelanta en las misiones. Por supuesto, entendemos como núcleo, el descubrimiento por parte de ella, que dará paso al inicio de la misión, y que concluirá con dos sucesos núcleos al final de la obra, muriendo Pablo y con ella siendo ajusticiada.

\section{La culpa del otro}

En La culpa del otro el primer suceso núcleo es el asesinato del marqués y la condena de los padres de María del Carmen. Este momento cambia la vida de la protagonista por completo al margen de la de los propios injustamente detenidos. La salida de prisión de Carolina y el encuentro entre María del Carmen y Juan Carlos, son dos sucesos núcleo que van de la mano. Por último, en los instantes finales de la obra, hay un suceso núcleo de carácter conclusivo, cuando Ludovico es acusado formalmente.

\section{Eloisa está debajo de un almendro}

Los instantes narrativos más importantes en esta obra los observamos al inicio de la misma con la carta que descubre Fernando por parte de su padre, demandando justicia para su amada. Posteriormente el encuentro entre el Fernando y Mariana que invita a ambos a luchar por lo que desean. El último suceso núcleo más importante, se da con la confesión por parte de Micaela después de tantos años.

\section{El clavo}

El inicio de la aventura por parte de Blanca y Javier es el primer suceso núcleo de la obra. El fin de la relación por parte de Blanca y la destinación de Javier son otros dos momentos de cambio narrativo principales que permiten el desarrollo propio de cada personaje. Encontramos un encuentro previo a la condena (otro suceso núcleo), que ayuda a reabrir de nuevo sus corazones, por lo que sería el tercero de los cuatro sucesos núcleo más relevantes.

\subsubsection{Conclusiones respecto a los puntos de inflexión}

- Las cuatro películas tienen un suceso núcleo al inicio del relato en el que hay un encuentro que propicia el amor, siendo diferente la desenvoltura de los mismos.

- Los sucesos núcleo se encuentran integrados siempre por personajes protagonistas, lo que ofrece un mayor peso a la importancia de los propios personajes. 
- Por el contrario, los personajes secundarios tienen una importancia deficiente en los sucesos núcleo del inicio y el nudo de cada historia, aunque sí muestran jerarquía en los núcleo finales, ya que (como en el caso de La culpa del otro o Eloísa está debajo de un almendro) puede ser implicados directos en la resolución del caso, con influencia negativa.

\subsection{Personajes redondos según su evolución en la narración}

Visto el análisis actancial y los sucesos núcleo, se pueden establecer cuáles son los personajes redondos que evolucionan a lo largo del relato, determinando el resto como planos, ya que no aportan nada más que una acción en un momento concreto, sin que este evolucione ni haya toma de parte del propio personaje.

\section{El 13-13}

Los personajes redondos que aparecen en escena a lo largo del relato son Pablo, Berta y Berkel. Los primeros cambian su forma de actuar al no saber compaginar completamente el amor y el trabajo. Desde el primer suceso núcleo, el primer encuentro en la calle, pasando por el reconocimiento de ambos como espías laboralmente competitivos, sufren una evolución basada en la adaptación. No obstante, el objetivo del cumplimiento del trabajo siempre permanece.

El caso de Berkel resulta interesante porque su doble función (confesor-director) se mantiene constante, pero siempre en función de las aventuras de sus empleados, algo a lo que tiene que acomodarse.

\section{La culpa del otro}

Esta película construye la narración alrededor de tres personajes redondos cuyas trayectorias varían en función de los hechos acontecidos. En primer lugar, la protagonista, María del Carmen, se muestra decidida a conocer la verdad sobre lo que sucedió con sus padres y también, a raíz del encuentro con Juan Carlos (otro punto de inflexión), compartir la investigación con él, que además es un ayudante de primer grado. El caso del personaje masculino ejemplifica como un personaje puede adaptarse a los cambios, ya sea con el encuentro del amor o con la puesta en marcha de la reapertura del caso.

Por otro lado, Carolina mantiene la esperanza de que lo sucedido antaño pueda esclarecerse y recuperar, así, el tiempo perdido, movimiento narrativo de un personaje redondo.

\section{Eloisa está debajo de un almendro}

Esta película es un ejemplo de cómo un hecho desconocido puede alterar el rumbo de multitud de personajes, tanto protagonistas como secundarios. Un suceso núcleo capital es la nota que deja el padre de Fernando y que pone de manifiesto el inicio de una nueva etapa para la vida del resto del coro. Tanto él como Mariana emprenden una aventura y eso conlleva cambios constantes e imprevistos que desembocan en el conocimiento de una realidad solapada.

Los sucesos núcleo en los que se comienza la investigación y se resuelve el caso, trastocan el trayecto de Micaela, quien finalmente será detenida, y de Edgardo quien descubre qué sucedió con su mujer. De esta manera, el espectador observa cómo evolucionan estos personajes.

\section{El clavo}


El personaje de Javier es paradigmático como personaje redondo, ya que los agentes externos que influyen en él trastocan su vida por completo: encuentro con Blanca, destinación como juez al pueblo, inicio del caso y descubrimiento de la asesina. En este sentido, Blanca también se muestra redonda al abandonar a Javier debido a su secreto y a decidir retornar con él, demostrándole su amor.

La implicación en el caso por parte de Juan, el secretario de Javier, le sitúa como personaje redondo ya que en él vemos aspectos característicos de este tipo de personaje, como la bondad, el respeto, la admiración (respecto a Javier) y la compasión (con Blanca).

\subsubsection{Aspectos sobre la redondez}

- Todos los personajes protagonistas son redondos ya que se encuentran expuestos a cambios constantes que permiten evolucionar al relato.

- Los personajes secundarios que adquieren una relación primaria con los protagonistas suelen ser redondos y las cuatro obras constan de ellos.

- Los sucesos núcleos son esenciales para poder desentrañar las personalidades cambiantes de los personajes.

- Cuando los protagonistas trabajan en parejas, los instantes narrativos que propician el primer encuentro entre ambos, dotan de cambios a su personalidad, ya que deben compaginar el amor con la investigación.

De la siguiente manera se podría entender que el esquema general de las obras escogidas podría resumirse como vemos en la siguiente imagen (Figura 5) con tres sucesos núcleos básicos.

Figura 5: El personaje en los sucesos núcleo. Fuente: elaboración propia.

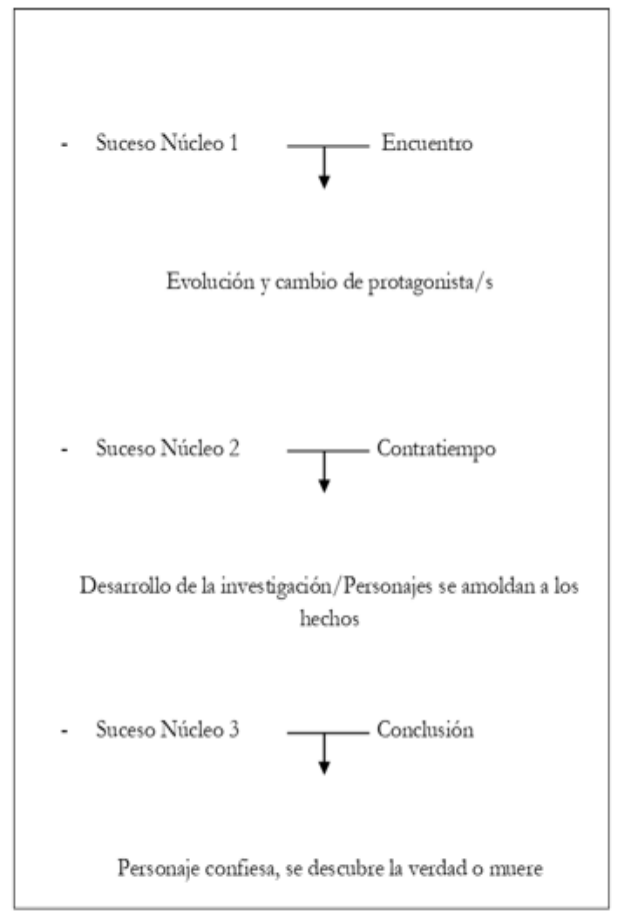




\subsection{Cuestiones generalistas finales: género, estereotipos y estratificación del personaje}

Para obtener conclusiones completas sobre los personajes en el cine detectivesco de Cifesa, analizaremos de manera breve, cuestiones que marcan los modos de representación del género en la producción elegida, la influencia del romanticismo y la importancia del establecimiento de jerarquías en torno estratos sociales del personaje protagonista y secundario.

- En primer lugar, los tintes expresionistas y nebulosos característicos de este tipo de obras, las encontramos en cada una de las películas.

- La frialdad de El clavo es especialmente visible cuando llega Javier a su nuevo destino. El ambiente terroso, la estratificación social (preponderancia de la religión), el uso de la muerte unida a las penurias sociales (hombre que usa un féretro como somier), promueven la inserción oscura del espectador en el caso.

- Eloísa está debajo de un almendro va más allá, aportando dosis de surrealismo casi mágico: castillos con fachadas exteriores que recuerdan a lugares encantados, pasadizos y puertas secretas que se abren y se cierran, mayordomos y seres encantados (en la mansión de Fernando) e incluso un laboratorio de investigación oculto. Teñida de comedia, mantiene curioso al espectador durante un largo periodo de la narración.

- Si en El clavo se muestra un costumbrismo argumental crudo, La culpa del otro, conjuga el humor tradicional (relación Atilano y Gregoria), alejándose de la adaptación de la obra de Jardiel Poncela y acercándose a la realidad especialmente en la división social.

- La estética que más evoca a las películas clásicas del cine negro estadounidense se da en El1313. La razón más factible sobre ello es porque pertenece al clásico cine de espías, con carreras de coches, países enfrentados (en este caso imaginarios) e historias de amor que acaban de manera trágica.

Respecto a los arquetipos, se concluye que:

- Siempre hay un galán, con estudios superiores que debe ayudar a la mujer.

- La mujer necesita del hombre para conseguir el objetivo.

- Existencia perenne del servicio doméstico como eje fundamental para la creación de sucesos satélite.

- El humor procede primero del hombre

o La culpa del otro: Atilano esclavizado por Gregoria

o El 13-13: canciones de amor que canta Pablo

o Eloísa está debajo de un almendro: Edgardo postrado en cama; Ezequiel y sus misterios.

o El clavo: la ironía en el rostro de Javier escuchando cantar mal a unos niños. 
- Mujer independiente:

o La culpa del otro: María del Carmen decide estudiar y vivir de la música.

o El 13-13: Berta es espía en un mundo de hombres; su amiga no quiere vivir con ningún varón, prefiere estar sola.

o Eloísa está debajo de un almendro: la tía de Mariana es una mujer independiente, aunque esté enamorada de Ezequiel.

o El clavo: Blanca vive su tragedia consigo misma.

En cuanto a la estratificación de personajes, encontramos que a excepción de El13-13 (ya que no sigue las mismas pautas de coro que el resto), todas las obras tienen puntos en común respecto a las clases sociales altas y bajas, representadas todas por una línea imaginaria en función del empleo y la posición que mantienen. De esta manera observamos que si en El 13-13, podemos encontrar en un nivel inferior a Krugerin, pero no deja de ser otro espía más, en el resto:

- Los personajes secundarios pertenecientes a la intendencia del hogar mantienen únicamente relaciones entre ellos (La culpa del otro y Eloísa está debajo de un almendro). Sucede lo mismo con los trabajadores rasos del archivo de El clavo.

- Las parejas, formadas por hombre y mujer, pertenecen al mismo ámbito social (Eloísa está debajo de un almendro), o se han cultivado para subir el nivel (La culpa del otro). De la misma manera, pueden ser compañeros de trabajo (El 13-13), aunque el hombre estará a un nivel superior (Pablo sobre Berta).

- El detective o policía profesional es representado al margen de la dicotomía entre la clase alta y la clase baja, ya sea adquiriendo todo el protagonismo en El 13-13, con rango en La culpa del otro o siendo un mero ayudante, aun así, respetado por su trabajo en El clavo y Eloísa está debajo de un almendro.

\section{Conclusiones}

La filmografía de Cifesa se caracterizó por internarse en distintos géneros, algunos con mayor suerte (folclore en la República) y otros con fracasos estrepitosos (Alba de América, ficción histórica final). Por ello, el análisis de las formas representativas del cine detectivesco en la productora valenciana permite delimitar un campo, que, si bien no es del todo desconocido para el gran público, gracias a la popularidad de algunas películas (Eloísa está debajo de un almendro y El clavo), se muestra disuelto en una densa filmografía caracterizada por un potente Star-System y un grupo de directores significativo en la época.

Aunque existe bibliografía que trata algunas de las obras escogidas, no existen publicaciones que engloben un grupo de películas de Cifesa dentro de un determinado género como es el policiaco. Es por ello que los paralelismos que se han mostrado en el estudio de campo reflejan un perfil característico de producción genérica durante los años 40 en su producción.

A raíz de lo expuesto, se debe hacer constar el bloque escogido como un referente dentro de 
la propia producción, que puede estar a la altura, en cuanto a temática se refiere, del grupo de películas folclóricas (Morena Clara, Torbellino, Nobleza baturra), películas históricas (Leona de Castilla, Agustina de Aragón, Alba de América) o comedias sainetescas (Los cuatro robinsones, El genio alegre, La verbena de la Paloma). Del mismo modo, debe aclararse que la producción de El clavo y Eloísa está debajo de un almendro tienen un mayor nivel estético-técnico que El 13-13 y La culpa del otro, además de haber sido llevadas al teatro y al cine durante décadas, por lo que su presencia debería suponer un plus para establecerse como bloque conjuntado.

Por otra parte, el análisis sinérgico entre el modelo actancial y la redondez del personaje según los instantes narrativos que suponen puntos de inflexión, ha permitido establecer las similitudes que existen entre las cuatro películas, siendo El13-13 la que dista en lo que a desarrollo narrativo se refiere, aun manteniendo pautas comunes respecto a las relaciones actanciales, debido esencialmente a su etiqueta purista de película noir.

\section{Referencias bibliográficas}

Andrade Boué, P. (2010). "Novela policíaca y cine policíaco: una aproximación". Ángulo Recto: Revista de estudios sobre la ciudad como espacio plural, 2 (1), 8-8.

Benavides, J.E. (2012). Consignas para escritores. Madrid: Editorial casa de Cartón.

Benet, V.J. (2014). "El cine negro español durante el franquismo: estilo y función política". Debats, 122, 10-18.

Betancur, A. (2005). Aproximación semiótica a la narrativa. Antioquia: Universidad de Antioquia.

Chatman, S. (1990). Historia y discurso: La estructura narrativa en la novela y el cine. Madrid: Taurus.

Chenovart, J. (2016). Elpersonaje secundario en el cine de Cifesa (tesis doctoral). Universitat Politècnica de València, Valencia, España.

Cifesa. (1939). "Noticiario Cifesa" (19).

Coma, J. (1991). Diccionario del cine negro. Barcelona: Plaza \& Janés.

Comas, A. (2004). El star system del cine español de posguerra. Madrid: T \& B Editores.

Fanés, F. (1989). Cifesa. La antorcha de los éxitos. Valencia: Filmoteca.

Forster, E.M. (1983). Aspectos de la novela. Madrid: Debate.

Franco i Giner, J. (1998). "El relato original de la tribu española a través de Cifesa". Gramay cal: revista insular de Filología, 2, 147-158.

García Jiménez, J. (1993). Narrativa audiovisual. Madrid: Cátedra.

Gledhill, Christine (1998), "Klute 1: A Contemporary Film Noir and Feminist Criticism”, Women in Film Noir, E. Ann Kaplan (ed.), Londres, British Film Institute: 20-34. 
Greimas, J.A. (1966). Semántica estructural: investigación metodológica. Madrid: Gredos.

Greimas, J.A. y Courtés, J. (1982). Semiótica. Diccionario razonado de la teoría del lenguaje. Madrid: Gredos.

Gutiérrez, B. (2016). "Porque te vi llorar o la educación sentimental de la España de la Posguerra". Arenal: Revista de historia de mujeres, 23(2), 247-266.

Hueso Montón, A. L. (2017). "El cine y su vinculación al mundo urbano". En E. Medina de la Viña. El cine negro y policial español: los años cincuenta y la especialización barcelonesa. Trípodos, 41, 15-34.

Medina de la Viña, E. (2017). "El cine negro y policial español: los años cincuenta y la especialización barcelonesa”. Trípodos, 41, 15-34.

Paszkiewicz, K. (2015). "A plena luz del día: Mataharis (2007) de Icíar Bollaín y la revisión del cine negro". Lectora: revista de dones i textualitat, 21, 91-92.

Prósper, J. (2004). Elementos constitutivos del relato cinematográfico. Valencia: Universidad Politécnica de Valencia.

Prósper, J. (2019). "El suspense cinematográfico: montaje y organización temporal”. Miguel Hernández Comnunication Journal, 10 (2), 303-321.

Rodríguez Fuentes, C. (2012). "Similitudes entre el cine negro clásico y el cine de un autor español de posguerra”. En D. Acle Vicente, F.J. Herrero Gutiérrez y M. González de Ávila (coords.) Expresión, análisis y crítica de los discursos audiovisuales (pp. 45-63). Tenerife: Sociedad Latina de Comunicación Social.

Russo, E.A. (1998). Diccionario de cine. Barcelona: Paidós.

Sánchez-Biosca, V. (2012). "Una nación de cartón-piedra. Las ficciones históricas de Cifesa". En I. Saz y Feran Archilés i Cardona (coords.) Discursos y prácticas del nacionalismo español en la época contemporánea (pp. 499-519). Valencia: Universitat de València.

Sánchez Noriega, J.L. (2008). "La cultura psicoanalítica en el cine negro americano". Revista de medicina y cine, 4, (1), 27-34. 
MHCJ Vol. 11 (2) | Año 2020 - Artículo n¹4 (165) - Páginas 277 a 296- mhjournal.org

\section{(c) $\underset{\mathrm{BY}}{\mathrm{BS}}$}

Licencia Creative Commons

Miguel Hernández Communication Journal

mhjournal.org

\section{Cómo citar este texto:}

Jorge Chenovart González (2020): El cine detectivesco de Cifesa a través de sus personajes, en Miguel Hernández Communication Journal, Vol. 11 (2), pp. 277 a 296. Universidad Miguel Hernández, UMH (ElcheAlicante). DOI: http://dx.doi.org/10.21134/mhcj.v11i0.334 